\title{
Enhancing Therapeutic Effects of Docetaxel-Loaded Dendritic Copolymer Nanoparticles by Co-Treatment with Autophagy Inhibitor on Breast Cancer
}

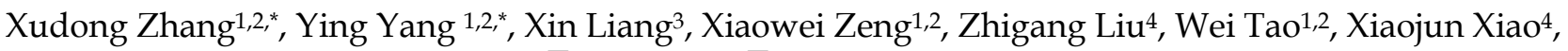 \\ Hongbo Chen ${ }^{1,2}$, Laiqiang Huang ${ }^{1,2}{ }^{\bowtie i n ~}$ Mei $^{1,2}{ }^{\bowtie}$ \\ 1. School of Life Sciences, Tsinghua University, Beijing 100084, P.R. China; \\ 2. The Shenzhen Key Lab of Gene and Antibody Therapy, Division of Life and Health Sciences, Graduate School at Shenzhen, Tsinghua University, \\ Shenzhen 518055, P.R. China; \\ 3. Key Laboratory of Regenerative Biology, South China Institute for Stem Cell Biology and Regenerative Medicine, Guangzhou Institutes of Bio- \\ medicine and Health, University of Chinese Academy of Sciences, Guangzhou, Guangdong, 510530, P.R. China; \\ 4. Institute of Allergy and Immunology, School of Medicine, Shenzhen University, Shenzhen 518060, P.R. China. \\ * These authors contributed equally to this work.
}

Corresponding authors: Lin Mei: Tel/Fax: +86 75526036736, E-mail: mei.lin@sz.tsinghua.edu.cn. Or Laiqiang Huang: Tel/Fax: +86 75526036052, E-mail: huanglq@sz.tsinghua.edu.cn.

() Ivyspring International Publisher. This is an open-access article distributed under the terms of the Creative Commons License (http://creativecommons.org/ licenses/by-nc-nd/3.0/). Reproduction is permitted for personal, noncommercial use, provided that the article is in whole, unmodified, and properly cited.

Received: 2014.06.18; Accepted: 2014.07.30; Published: 20I4.08.15

\begin{abstract}
Dendrimers are synthetic nanocarriers that comprise a highly branched spherical polymer as new, efficient tools for drug delivery. However, the fate of nanocarriers after being internalized into cells has seldom been studied. Docetaxel loaded dendritic copolymer H40-poly(D,L-lactide) nanoparticles, referred to as "DTX-H40-PLA NPs", were prepared and used as a model to evaluate whether the NPs were sequestered by autophagy and fused with lysosomes. Besides being degraded through the endolysosomal pathway, the DTX-loaded H40-PLA NPs were also sequestered by autophagosomes and degraded through the autolysosomal pathway. DTX-loaded H40-PLA NPs may stop exerting beneficial effects after inducing autophagy of human MCF-7 cancer cells. Co-delivery of autophagy inhibitor such as chloroquine and chemotherapeutic drug DTX by dendritic copolymer NPs greatly enhanced cancer cell killing in vitro, and decreased both the volume and weight of the tumors in severe combined immunodeficient mice. These findings provide valuable evidence for development of nanomedicine such as dendritic copolymer NPs for clinical application.
\end{abstract}

Key words: Nanomedicine; Endocytosis; Autophagy; Docetaxel; Chloroquine; Dendrimers.

\section{Introduction}

Nanomedicine refers to the use of nanotechnology for diagnosis, monitoring and therapy of various diseases [1]. Various nanocarriers for diagnosis and treatment based on degradable polymers and non-degradable materials (e.g. polymeric nanoparticles, liposomes, micelles, solid lipid nanoparticles, carbon nanotubes, gold nanoparticles, silica nanoparticles and dendrimers) have been developed [1-3]. As branched, synthetic polymers with layered architectures, dendrimers are highly promising in several biomedical and pharmaceutical applications such as drug delivery [2-4]. It is characterized by an extensively branched 3D structure that provides a high degree of surface versatility and functionality. By having unique properties such as uniform size, high degree of branching, multivalency, water solubility, 
well-defined molecular weight and available internal cavities, these dendrimers are potentially applicable to drug delivery [1-5]. However, the fate of the dendrimers after being internalized into cells has rarely been studied. Moreover, there have been public concerns on the safety issue of dendrimers because the intracellular pharmacokinetics of them, i.e. adhesion, distribution, metabolism and excretion, is still unclear [6].

Autophagy is a basic cellular catabolic mechanism that involves intercellular degradation of dysfunctional cellular components or foreign invaders through the lysosomal machinery in which cytoplasmic materials are degraded by being sequestered into double membrane vesicles and transported to lysosomes $[7,8]$. Autophagy plays a vital role in cytoplasmic renewal, elimination of intercellular aggregate-prone proteins and clearance of pathogens [9]. Till now, non-degradable nanoparticles, such as gold, silica and $\mathrm{TiO}_{2}$ nanoparticles, have been reported to induce oxidative damage and autophagy $[10,11]$. In our previous study, poly (lactic-co-glycolic acid) (PLGA)-based nanoparticles induced autophagy during which autophagosomes enwrapped the nanoparticles and delivered them to lysosomes for degradation. Moreover, polyethylene glycol- and D-a-tocopheryl polyethylene glycol 1000 succinate (TPGS)-modified PLGA-based nanoparticles are able to induce far more autophagosomes than nonmodified PLGA-based ones [12]. However, whether dendrimers are sequestered by autophagy and degraded through the autophagic pathway remains unknown. On the other hand, autophagy suppresses tumor suppression by removing damaged organelles/proteins and limiting cell growth and genomic instability [13-14]. Nevertheless, upon tumorigenesis, cancer cells confer stress tolerance such as acid environment, hypoxia and deficiency of nutrition through autophagy, thus maintaining tumor cell survival [14]. After being activated in response to a variety of chemotherapeutic drugs, autophagy decreases their therapeutic effects and resists cell death [15]. Therefore, chemotherapeutic drugs have been combined with autophagy inhibitors such as 3-methyladenine (3-MA) and chloroquine (CQ) to enhance tumor cell death in vitro and in vivo [16, 17]. Thereby motivated, docetaxel (DTX)-loaded nanoparticles made of dendritic polymers (H40-PLA) named DTX-loaded H40-PLA nanoparticles were employed in this study to evaluate whether dendrimers are sequestered by autophagy and degraded through the autophagic pathway.

\section{Materials and methods}

\section{Materials}

$\mathrm{CQ}$, 3-MA, stannous octoate $\left(\mathrm{Sn}(\mathrm{Oct})_{2}\right)$ and D,L-lactide (LA) were purchased from Sigma-Aldrich (St. Louis, MO). Boltorn ${ }^{\circledR} \mathrm{H} 40$ (H40, a dendritic polyester with 64 hydroxyl terminal groups per molecule, $M_{\mathrm{n}}$ 2833) was obtained from Perstorp Polyols AB Co., Sweden. Docetaxel was from Shanghai Jinhe Bio-tech Co., Ltd. (Shanghai, China). Acetonitrile and methanol were purchased from EM Science (HPLC grade, Mallinckrodt Baker, USA). All other chemicals of highest quality were commercially available. Antibodies against LC3 and LAMP1 were from Cell Signaling Technology, Inc. (Danvers, MA). Antibody against $\beta$-actin was obtained from Abmart, Inc (Shanghai, China).

\section{Synthesis and characterization of dendritic copolymer H40-PLA}

Dendritic copolymer H40-PLA was synthesized by the ring opening polymerization (ROP) of LA with $\mathrm{H} 40$ as the macro-initiator and $\mathrm{Sn}(\mathrm{Oct})_{2}$ as the catalyst. LA (4.58 g, $31.77 \mathrm{mmol}), \mathrm{H} 40(0.50 \mathrm{~g}, 11.29 \mathrm{mmol}$ of hydroxyl groups), and $\mathrm{Sn}(\mathrm{Oct})_{2}(0.013 \mathrm{~g}, 0.1 \mathrm{~mol} \%$ of monomer) were added in a glass tube which was connected to a vacuum system. An exhausting-refilling process with argon was then repeated three times. The tube was sealed, heated to $150^{\circ} \mathrm{C}$ in oil bath for $12 \mathrm{~h}$, and then cooled to room temperature. The crude product was dissolved in tetrahydrofuran (THF) and passed through a neutral alumina column. Then the mixture was concentrated and precipitated in cold diethyl ether to generate white powders H40-PLA. The final product was collected by filtration and dried under vacuum at $40^{\circ} \mathrm{C}$ for $24 \mathrm{~h} .{ }^{1} \mathrm{H}$ NMR (Bruker AMX 500) was used to confirm the structures of dendritic copolymer H40-PLA which dissolved in $\mathrm{CDCl}_{3}$. Molecular weight of the H40-PLA was determined by GPC (Waters GPC analysis system with RI-G1362A refractive index detector, Waters Corp., Milford, MA, USA) with THF as the eluent at the flow rate of $1 \mathrm{~mL} / \mathrm{min}$. Molecular weight and polydispersity index were estimated using standard polystyrene samples.

\section{Plasmid and transfection}

DsRed-Rab5, DsRed-Rab7 and Flag-Rubicon plasmids were from Addgene. DsRed-LC3 plasmids were prepared in our laboratory. KSHV Flag-vBcl-2 plasmid was kindly provided by Professor Beth Levine, University of Texas Southwestern Medical Center. All plasmid constructs were confirmed by DNA sequencing. Cells were transiently transfected with the plasmids using lipofectamine 2000 (Invitrogen, 
Carlsbad, CA, USA) according to the manufacturer's instructions.

\section{Formulation of coumarin-6-loaded and DTX-loaded H40-PLA nanoparticles}

Coumarin-6-loaded and DTX-loaded H40-PLA nanoparticles were prepared by a modified nanoprecipitation method [18]. In brief, $10 \mathrm{mg}$ coumarin- 6 or $10 \mathrm{mg}$ DTX powders were dissolved in $8 \mathrm{~mL}$ of acetone with $100 \mathrm{mg}$ H40-PLA copolymer by vortexing and sonication, respectively. The mixture was dropwise added into $100 \mathrm{~mL}$ of aqueous solution (including $0.03 \%$ TPGS) under stirring. The suspension was then stirred uncovered overnight to remove acetone completely. Then the suspension was centrifuged at 20,000 rpm for $30 \mathrm{~min}$. The precipitation was then washed three times with sterile water. Finally, the dispersed solution was lyophilized for 2 days for further use.

\section{Characterization of nanoparticles}

Particle size and zeta potential were measured by Malvern Mastersizer 2000 (Zetasizer Nano ZS90, Malvern Instruments Ltd., UK). Zeta potential is an indicator of the surface charge and colloidal stability of particles. Before measurement, freshly prepared NPs were appropriately diluted. All measurements were carried out at room temperature after $10 \mathrm{~min}$ of equilibration. The data were the averages of three measurements. Surface morphology of the nanoparticles was examined by field emission scanning electron microscopy (FESEM, JEOL JSM-6301F, Tokyo, Japan). To prepare samples for FESEM, the H40-PLA NPs were fixed on a stub by a double-sided sticky tape and then coated with platinum layer by JFC-1300 automatic fine platinum coater (JEOL, Tokyo, Japan) for 60 s. The H40-PLA NPs were further observed by transmission electron microscopy (TEM, Tecnai G2 20, FEI Company, Hillsboro, Oregon, USA). Sample was dropped onto a copper grid coated with a carbon membrane. The grid was allowed to dry before characterization.

\section{Drug loading and drug encapsulation efficiency}

To determine the drug loading content (LC) and drug encapsulation efficiency (EE), DTX-H40-PLA NPs at a predetermined amount were dissolved in 1 $\mathrm{mL}$ of dichloromethane under vigorous vortexing. The solution was transferred to $5 \mathrm{~mL}$ of mobile phase consisting of deionized water and acetonitrile (50:50, $\mathrm{v} / \mathrm{v})$. A nitrogen stream was introduced to evaporate dichloromethane for about $15 \mathrm{~min}$, and then a clear solution was obtained for HPLC analysis (LC 1200, Agilent Technologies, Santa Clara, CA, USA). A reverse-phase $\mathrm{C}_{18}$ column $\left(150 \times 4.6 \mathrm{~mm}, 5 \mu \mathrm{m}, \mathrm{C}_{18}\right.$, Agilent Technologies, CA, USA) was used at $35^{\circ} \mathrm{C}$. The flow rate of mobile phase was set at $1 \mathrm{~mL} / \mathrm{min}$. The column effluent was detected using a UV detector at $\lambda_{\max }$ of $227 \mathrm{~nm}$ [19]. The measurement was performed in triplicate. LC and EE of the DTX-H40-PLA NPs were calculated by previously described methods [12].

\section{Cell culture}

Human breast carcinoma cell line MCF-7 was purchased from American Type Culture Collection (ATCC, Rockville, MD). MCF-7 cells were cultured in Dulbecco's Modified Eagle's Medium (DMEM) supplemented with $10 \%$ Fetal Bovine Serum (FBS).

\section{Cellular uptake of coumarin-6-loaded H40-PLA NPs}

Coumarin-6 was used as a model fluorescent molecule that was formulated in dendritic copolymer H40-PLA NPs. Cellular uptake of coumarin-6 loaded H40-PLA NPs by MCF-7 cells was detected. Non-transfected or DsRed-Rab5 and DsRed-Rab7 cells were incubated with $100 \mu \mathrm{g} / \mathrm{mL}$ coumarin-6-loaded H40-PLA NPs at $37^{\circ} \mathrm{C}$ for $2 \mathrm{~h}$. For lysosome detection, the cells were incubated with Lyso-Tracker Red for $1 \mathrm{~h}$. Then the cells were washed with PBS three times, fixed by $4 \%$ paraformaldehyde for $20 \mathrm{~min}$, stained with DAPI for $15 \mathrm{~min}$ and washed three times with PBS. Confocal microscopy was performed on a FLUO-VIEW laser scanning confocal microscope (Olympus, FV1000, Olympus Optical, and Japan) in the sequential scanning mode using a 60-100 xobjective.

\section{Autophagy assays}

DsRed-LC3 transfected MCF-7 cells were transfected with $100 \mu \mathrm{g} / \mathrm{mL}$ drug-free H40-PLA NPs, 100 $\mu \mathrm{g} / \mathrm{mL}$ coumarin-6-loaded H40-PLA NPs, $1 \mu \mathrm{M}$ DTX, DTX-H40-PLA NPs (equal to $1 \mu \mathrm{M}$ DTX), $10 \mathrm{mM}$ 3 -MA or $30 \mu \mathrm{M}$ CQ for $24 \mathrm{~h}$. And then fixed in $4 \%$ paraformaldehyde. The cells with fluorescent dots representing DsRed-LC3 translocation were counted by confocal microscopy as described in Hoyer-Hansen'work M [20]. In brief, the percentage of cells with DsRed-LC3 translocation into dots (250 cells/sample, with over five LC3-positive dots) was counted in DsRed-LC3 expressing cells. LC3II protein level was detected by western blotting using the anti-LC3 antibody.

\section{Immunoblotting and immunofluorescence assays}

Immunoblotting analysis was performed as described in Liang $C^{\prime}$ work [21]. In brief, cell lysates were resolved on 12\% SDS-PAGE and analyzed by immunoblotting using LC3 antibody, followed by enhanced chemiluminescence (ECL) detection 
(Thermo Scientific). Immunofluorescence assay was performed as described in Liang $C^{\prime}$ work [22]. The frozen sections were incubated in PBS for $15 \mathrm{~min}$ to remove the embedding medium. The specimens were blocked with the buffer containing 3\% BSA and 0.5\% Triton X-100 for 30 minutes. The specimens were subsequently, incubated with LC3B primary antibody (1:50 in 3\% BSA) overnight and then washed three times with PBS for 5 min each. They were then incubated with TRITC secondary antibody (KPL) diluted in 3\% BSA at room temperature in the dark for $1 \mathrm{~h}$. Finally, confocal microscopy was performed on a FLUO-VIEW laser scanning confocal microscope (Olympus, FV1000, Olympus Optical, Japan) in sequential scanning mode using a $20 \times$ objective.

\section{In vitro cytotoxicity of H40-PLA NPs}

MCF-7 cells were seeded in 96-well plates at the density of $5 \times 10^{3}$ cells per well in $100 \mu$ l of medium and incubated overnight. Thereafter the cells were co-treated with DTX-H40-PLA NPs at the concentration equivalent to $0.25-25 \mu \mathrm{g} / \mathrm{mL}$ docetaxel and $30 \mu \mathrm{M}$ CQ. The MCF-7 cells were incubated with these regents for 24, 48 and $72 \mathrm{~h}$. Before harvest, the culture media were replaced with fresh ones containing MTT $(5 \mathrm{mg} / \mathrm{mL})$ and incubated for another $4 \mathrm{~h}$. Absorbance was measured at $570 \mathrm{~nm}$.

\section{In vivo anti-tumor assay with xenograft severe combined immunodeficient mice model}

All animal experiments have been approved by the Institutional Animal Care and Use Committee of Tsinghua University Shenzhen Graduate School. Female severe combined immunodeficient (SCID) mice were purchased from the Institute of Laboratory Animal Sciences, Chinese Academy of Medical Science. MCF-7 cells $\left(2 \times 10^{6}\right.$ cells/mouse $)$ were inoculated subcutaneously to mice at the right axilla. Tumors were measured by vernier caliper and the volume $(V)$ was calculated as $V=d^{2} \times D / 2$, where $d$ and $D$ are the shortest and the longest diameters of the tumor in mm respectively [23]. When the tumor volume reached around $30 \mathrm{~mm}^{3}$ (designated as the 0 day), treatments were performed. The mice were randomly divided into four groups (each group has 5 animals, $n$ $=5$ ). Saline was used as control. DTX-loaded H40-PLA NPs were injected via peritoneal cavity at a single dose of $10 \mathrm{mg}$ DTX / $\mathrm{kg}$ in PBS, $50 \mathrm{mg} / \mathrm{kg}$ CQ in PBS and $10 \mathrm{mg}$ DTX / $\mathrm{kg}$ in PBS in combination with $50 \mathrm{mg} / \mathrm{kg}$ CQ in PBS on days $0,2,4,6,8,10$ and 12 respectively. The mice were sacrificed by cervical decapitation 12 days after treatment. The terminal tumor weight (mg) was measured to evaluate the antitumor activity.

\section{Statistical methodology}

All results are reported as mean \pm S.E.M. of three independent experiments. Comparisons were performed using a two-tailed paired Student's $t$ test (* $P<0.05$, ${ }^{* *} P<0.01$, $\left.{ }^{* * *} P<0.001\right)$.

\section{Results and discussion}

\section{Synthesis and characterization of dendritic copolymer H40-PLA}

The synthetic route of dendritic copolymer H40-PLA is shown in Fig.1A. H40-PLA was synthesized by the ROP of LA using $\mathrm{H} 40$ as the multi-hydroxyl initiator and $\mathrm{Sn}(\mathrm{Oct})_{2}$ as the catalyst under an argon atmosphere at $150^{\circ} \mathrm{C}$ for $12 \mathrm{~h}$. Fig.1B presents the ${ }^{1} \mathrm{H}$ NMR spectrum of H40-PLA. The characteristic peak signals from initiator $\mathrm{H} 40$ and monomer LA repeating units were observed: a $(\delta=5.18 \mathrm{ppm}$, LA repeating unit: $\left.-\mathrm{CHCH}_{3}\right), \mathrm{b}(\delta=1.56 \mathrm{ppm}$, LA repeating unit: $\left.-\mathrm{CHCH}_{3}\right), \mathrm{c}(\delta=4.35 \mathrm{ppm})$ and $\mathrm{d}(\delta=$ $1.47 \mathrm{ppm})$ were assigned to the terminal methane protons $\left(-\mathrm{CHCH}_{3} \mathrm{OH}\right)$ and methyl protons $\left(-\mathrm{CHC} \underline{H}_{3} \mathrm{OH}\right)$ of $\mathrm{H} 40-\mathrm{PLA}$, respectively. The peaks at $1.23 \mathrm{ppm}$ and $4.20 \mathrm{ppm}$ corresponded to the protons of the methyl and methylene groups of Boltorn ${ }^{\circledR} \mathrm{H} 40$. As evidenced by the ${ }^{1} \mathrm{H}$ NMR spectrum, H40-PLA was of a dendrimer-like structure. The molecular weight $\left(M_{n}\right)$ of the copolymer was measured by GPC. The $M_{\mathrm{n}}$ and polydispersity index (PDI) evaluating from GPC analysis were $2.6 \times 10^{4}$ and 1.6 , respectively.

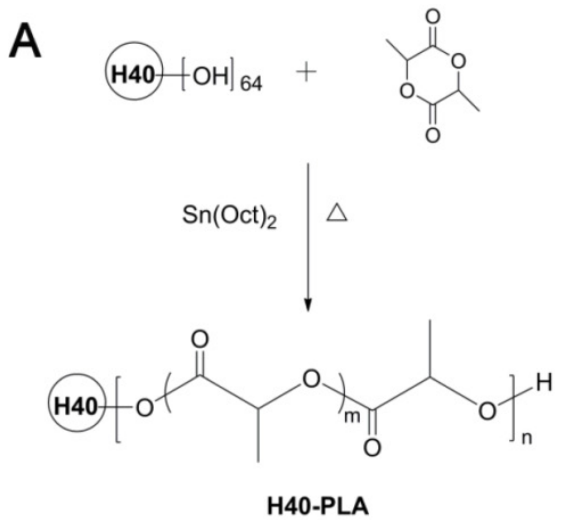

B

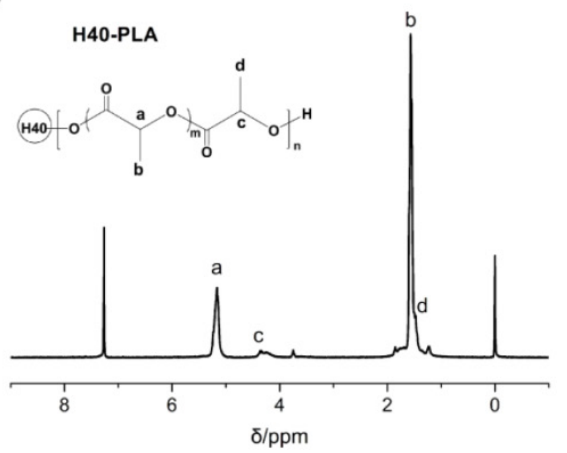

Figure I. (A) Synthesis scheme of dendrimer-like copolymer H40-PLA. (B) Typical IH NMR spectra of H40-PLA. 


\section{Preparation and characterization of NPs}

Drug-free, coumarin-6-loaded and DTX-H40PLA NPs were prepared by a modified nanoprecipitation method (Fig. 2A) [18]. Particle size and surface properties of the nanoparticles play a key role in drug release, cellular uptake and biodistribution [24,25]. Dynamic light scattering was carried out to measure the size and size distribution of these H40-PLANPs. As shown in Fig. 2B and Table 1, the average hydrodynamic size of these H40-PLA NPs were about 100 $\mathrm{nm}$ in diameter, falling within the optimum particle size range of $20-200 \mathrm{~nm}$ for prolonged circulation, accumulation in tumor tissue, enhanced diffusion within tissue and uptake by cancer cells [18,24-26]. FESEM and TEM images shows that the H40-PLA NPs have a nearly spherical shape (Fig. 2C and D).
Zeta potential of nanoparticles determines their stability in suspensions as well as cellular uptake [18, 24, 26]. Therefore, the zeta potential of these H40-PLA NPs was also measured. As shown in Table 1, the zeta potentials of the DTX-loaded and drug-free H40-PLA NPs are -19.6 and $-21.8 \mathrm{mV}$, respectively. Besides, the drug LC and EE of DTX-H40-PLA NPs reached around $9.53 \%$ and $94.31 \%$, respectively, which were conducive to drug delivery.

Table I. Characterization of H40-PLA NPs.

\begin{tabular}{llllll}
\hline Group & Size $(\mathrm{nm})$ & PDI & ZP $(\mathrm{mV})$ & LC $(\%)$ & EE $(\%)$ \\
\hline DTX-loaded NPs & $107.3 \pm 4.6$ & 0.129 & $-19.6 \pm 2.5$ & 9.53 & 94.31 \\
Drug-free NPs & $98.6 \pm 3.8$ & 0.106 & $-21.8 \pm 3.9$ & 0 & 0
\end{tabular}

Size $=$ The diameter of particles, $\mathrm{PDI}=$ Polydispersity index, $\mathrm{ZP}=$ Zeta potential, LC $=$ Loading content, $\mathrm{EE}=$ Encapsulation efficiency, $n=3$.
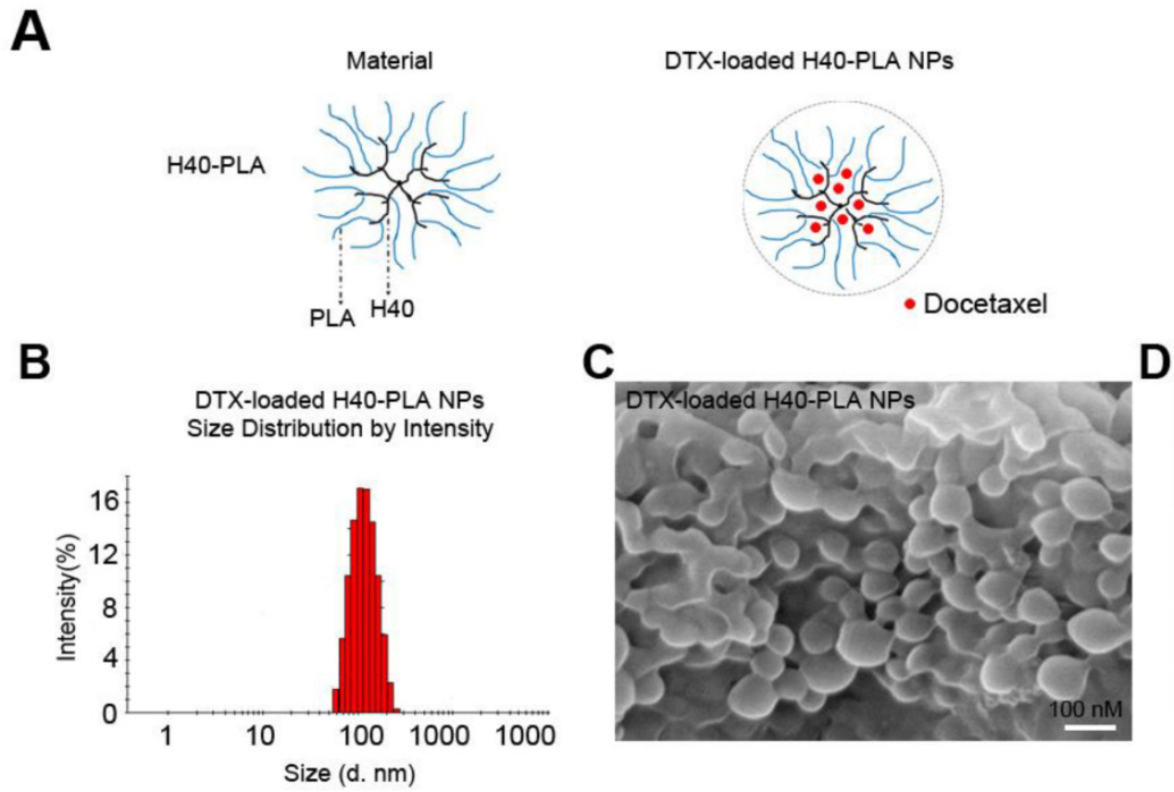

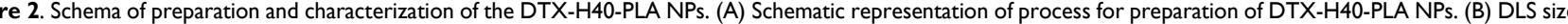
distribution of DTX-H40-PLA NPs. (C) FESEM image of the DTX-H40-PLA NPs. Scale bars: $100 \mathrm{~nm}$. (D) TEM image of the DTX-H40-PLA NPs. Scale bars: I00 nm.

\section{Cellular uptake of NPs}

Mammalian cells can absorb nutrients such as glucose and amino acid from the external environment. This process of bulk transport of material into a cell is referred to as endocytosis, either being dependent or independent on clathrin [27]. Nanoparticles based on biodegradable polymers such as PLA, PLGA and chitosan tend to enter mammalian cells through clathrin-dependent endocytosis [28,29]. However, the fate of NPs after being internalized into the cells has scarcely been studied. To this end, Boltorn ${ }^{\circledR}$ H40-PLA was synthesized in our group and used as a model dendritic polymer to investigate the trafficking within cells, and a green fluorescent dye (coumarin-6) was used for tracing. In order to inves- tigate whether NPs are degraded through the endo-lysosomal pathway, DsRed-Rab5 and DsRed-Rab7 were used to label the early endosome and late endosome respectively for which Rab GTPases Rab5 and Rab7 are the most important organelle identity markers [30]. The DsRed-Rab5 and DsRed-Rab7 transfected MCF-7 cells were treated with coumarin-6-loaded H40-PLA NPs for $1 \mathrm{~h}$. The NPs were internalized by the cells efficiently and parceled in a number of spherical particles therein (Fig. 3A). In the meantime, these coumarin-6-loaded spherical particles were co-localized with DsRed-Rab5 labeled early endosomes and DsRed-Rab7 labeled late endosomes (Fig. 3 B and C). Hence, the H40-PLA NPs could be efficiently absorbed by mammalian cells. To confirm the final destination of the H40-PLANPs, 
Lyso-Tracker Red probes were used to detect lysosomes. As expected, most H40-PLA NPs were co-localized with the lysosomes and degraded within them (Fig. 3D). In summary, the H40-PLA NPs were subjected to efficient uptake by mammalian cells through endocytosis and translocation into lysosomes for degradation finally.

\section{Autophagy induced by dendrimer-based NPs}

Autophagy is the process of bulk degradation and recycling of long-lived proteins, macromolecular aggregates, and damaged intracellular organelles. Our previous work showed that mammalian cells could sequester cytoplasmic PLGA-based nanoparticles and degrade them through the autolysosomal pathway [6, 12]. However, whether the autophagic pathway is involved in the degradation of dendritic polymers is still unknown. LC3, an au-

tophagy related gene (the homology gene of Atg8 in mammalian cells), has been widely used to detect autophagy [31]. When autophagy is initiated, LC3 is cut on the C-terminal and produces LC3II protein which is then transferred on the autophagosomes. In order to detect the formation of autophagosome (LC3-positive vesicle), the fluorescent autophagy marker DsRed-LC3 was expressed to measure autophagy [31]. To detect whether the H40-PLA NPs induce autophagy, DsRed-LC3 transfected MCF-7 cells were treated with drug-free H40-PLA NPs for 24 $h$, in which substantial autophagosomes were induced (Fig. 4A). Meanwhile, the levels of LC3-II proteins also increased (Fig. 4B). Accordingly, the H40-PLA NPs that were enwrapped by the autophagosomes could induce autophagy.

B
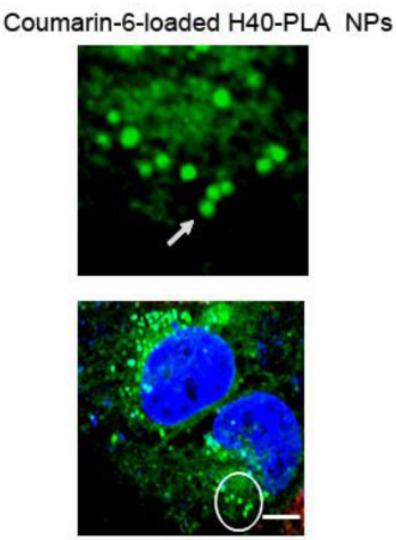

C

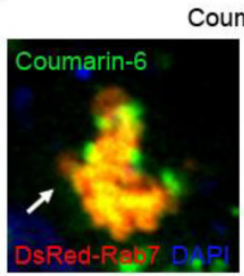

Coumarin-6-loaded H40-PLA NPs
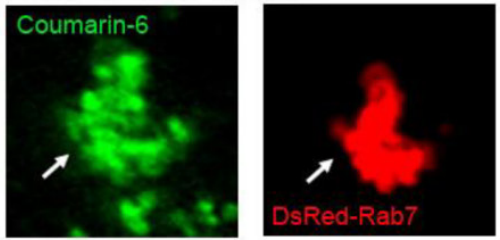

D

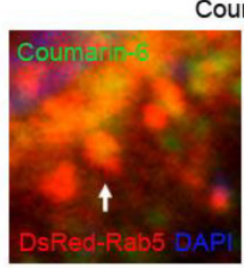

Coumarin-6-loaded H40-PLA NPs
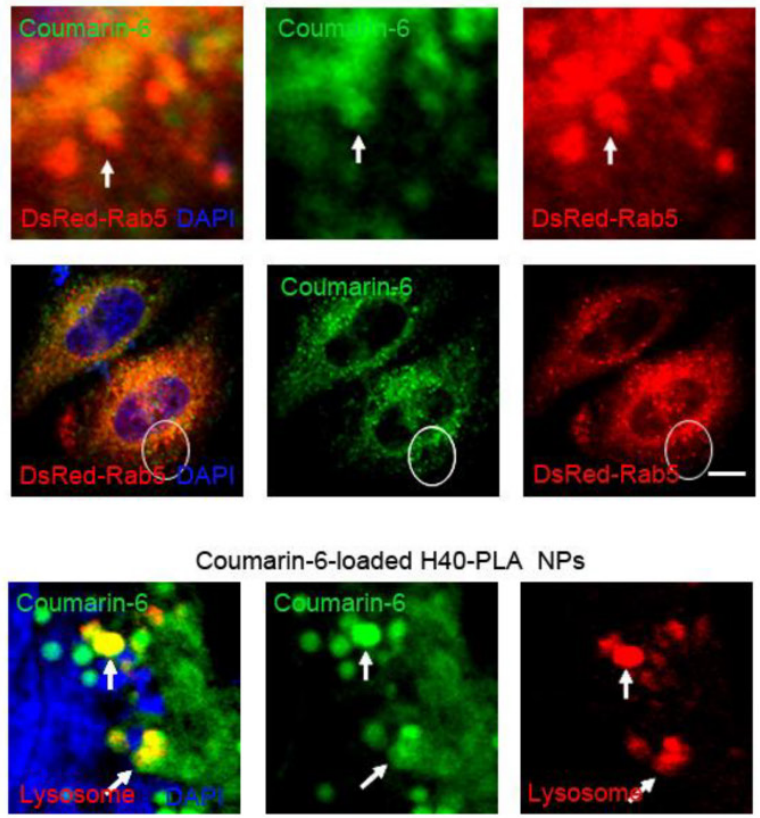

Coumarin-6-loaded H40-PLA NPs
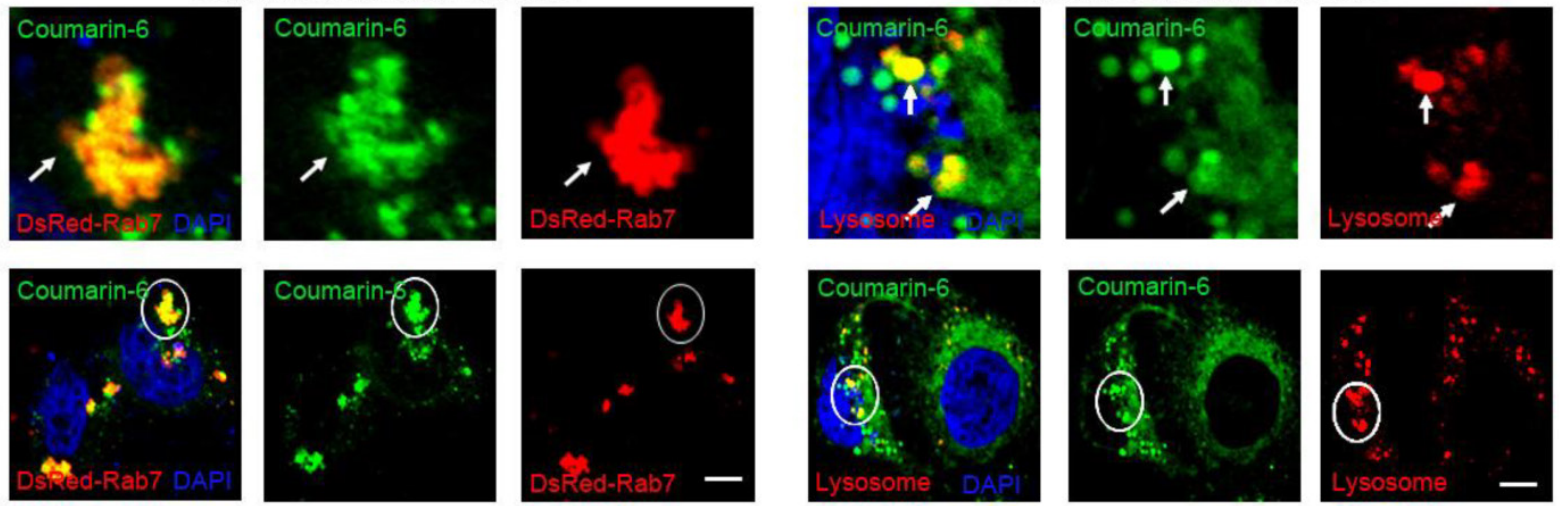

Figure 3. H40-PLA NPs were uptaken through endocytosis by the cells. Representative images of MCF-7 cells, DsRed-Rab5 transfected MCF-7 cells and DsRed-Rab7 transfected MCF-7 cells were treated with $100 \mu \mathrm{g} / \mathrm{mL}$ coumarin-6-loaded H40-PLA NPs for $2 \mathrm{~h}$. For lysosome detection, the MCF-7 cells were treated with I00 $\mu \mathrm{gg} / \mathrm{mL}$ coumarin-6-loaded H40-PLA NPs for $2 \mathrm{~h}$, and then co-treated with Lyso-Tracker Red probes for $30 \mathrm{~min}$. The above images are the enlarged ones in the white collar on the underside images. Scale bars: $10 \mu \mathrm{m}$ 
A
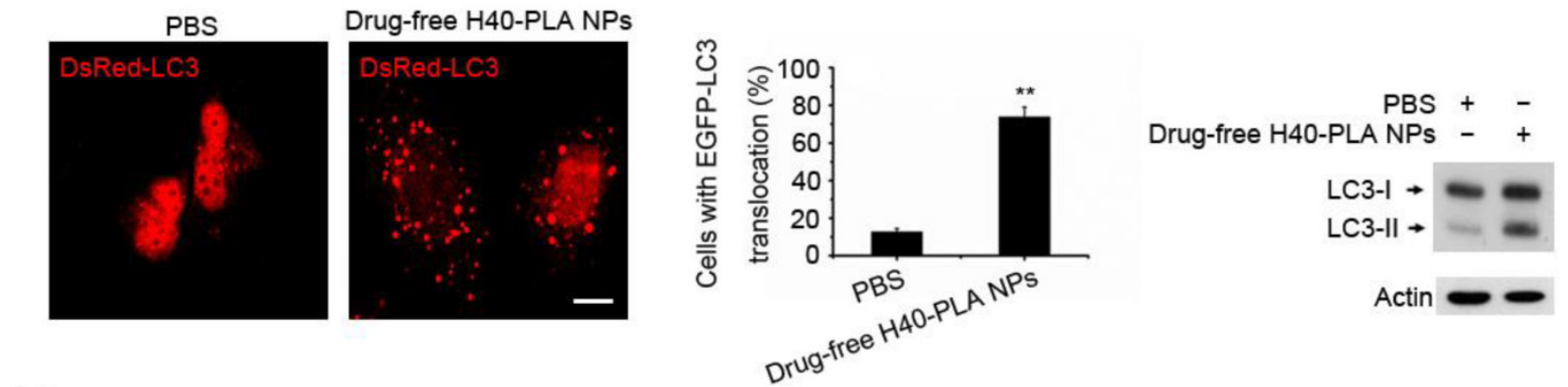

C

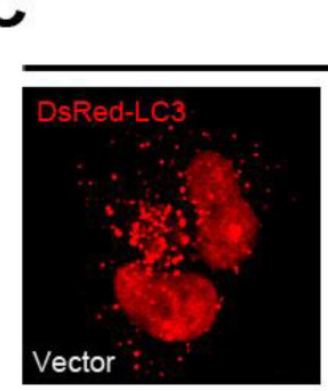

Drug-free H40-PLA NPs
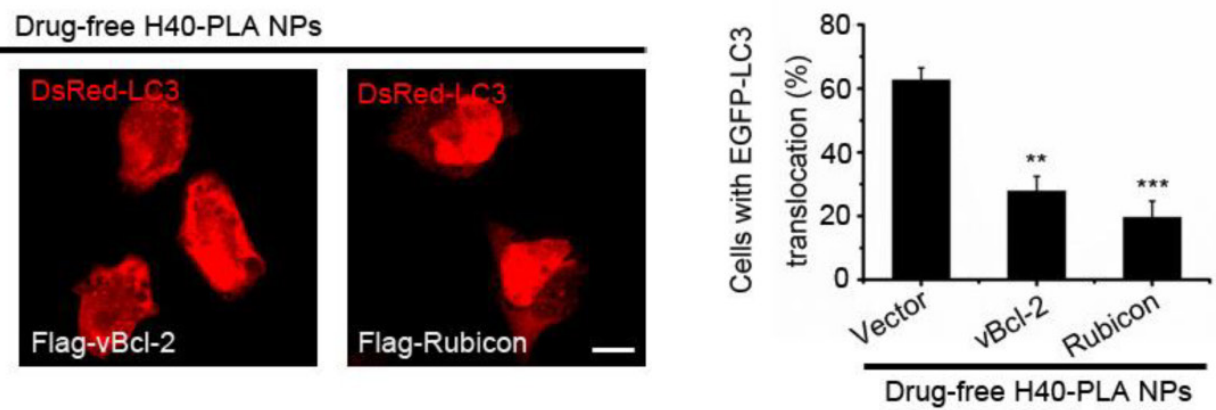

Figure 4. H40-PLA NPs induced autophagy and were sequestered by the autophagosomes. (A, B) Representative images and quantification of MCF-7 cells with EGFP-LC3 vesicles (autophagosomes). DsRed-LC3 transfected cells were treated with $100 \mu \mathrm{g} / \mathrm{mL}$ drug-free H40-PLA NPs for $24 \mathrm{~h}$. Scale bars: $10 \mu \mathrm{m}$. Data are shown as the mean \pm S.E.M. $* \mathrm{P}<0.05$, * $\mathrm{P}<0.01$, *** $\mathrm{P}<0.00 \mathrm{I}$ compared to controls. LC3I/II protein levels were analyzed by western blotting in the MCF-7 cells. (C) DsRed-LC3 cells were co-transfected with Flag-Rubicon and Flag-vBcl-2 and then treated with $100 \mu \mathrm{g} / \mathrm{mL}$ drug-free H40-PLA dendrimers for 24 h. Scale bars: $10 \mu \mathrm{m}$. Data are shown as the mean \pm S.E.M. $* P<0.05$, $* *$ $P<0.01$, *** $P<0.001$ compared to controls.

\section{Regulation of dendrimer-based NPs-induced autophagy by Class III PI3K complex}

Our previous work showed that Class III PI3K complex could regulate the autophagy induced by PLGA-based nanoparticles [12]. Thus, we herein tested whether it functioned the same under the action of H40-PLANPs. Two different Beclin1 proteins containing Class III PI3K complex, viz., one including Atg14L, Beclin1, hVps34, hVps15 and Bcl-2 family members, and the other including Rubicon, UVRAG, Beclin1, hVps34 and hVps15, have been identified in the cells [32]. Bcl-2 and Rubicon negatively regulate the two Class III PI3K complexes respectively [32], so the HA-tagged Rubicon and Flag-tagged Kaposi's sarcoma-associated herpes virus Bcl-2 (KSHV vBcl-2) transfected MCF-7 cells were treated with the drug-free H40-PLA NPs for $24 \mathrm{~h}$ to detect the resultant regulation of autophagy. Interestingly, overexpression of Rubicon and vBcl-2 significantly inhibited the formation of autophagosomes induced by the dendritic copolymer H40-PLA NPs (Fig. 4C). Thus, autophagosomes induced by the H40-PLA NPs could also be regulated by Class IIIPI3K complex.

\section{Degradation pathway of dendritic copolymer H40-PLA NPs in MCF-7 cells}

In our previous research, PLGA-based nanopar- ticles could induce autophagy, and autophagosomes degraded the nanoparticles by enwrapping and delivering them to lysosome. In other words, autolysosomes in the cells managed to capture and degrade the PLGA-based nanoparticles [12]. Hence, H40-PLA NPs may also be degraded through the autolysosomal pathway. To this end, the DsRed-LC3 transfected MCF-7 cells were treated with the coumarin-6-loaded H40-PLA NPs for $24 \mathrm{~h}$. Subsequently, the H40-PLA NPs were sequestered within the autophagosomes (Fig. 5A). Moreover, the autophagosomes were then translocated to fuse with lysosome for degradation (Fig. 5B). These findings demonstrated that the H40-PLA NPs could also be degraded through the autophagic pathway.

\section{Enhanced drug delivery by DTX-loaded H40-PLA NPs in combination with autophagy inhibitors}

In vitro studies

Autophagy suppresses tumors by removing damaged organelles/proteins and limiting cell growth and genomic instability [12-14]. Similar to other events, autophagy is a double-edged sword. In case of tumorigenesis, cancer cells confer stress tolerance such as acid environment, hypoxia and deficiency of nutrition by utilizing autophagy, thereby 
maintaining tumor cell survival [6, 12-14]. The cancer cells also activate autophagy in response to various chemotherapeutic drugs, which resist cell death and decrease the curative effect [15]. Therefore, co-delivery of chemotherapeutic drug and autophagy inhibitors may exert satisfactory therapeutic effects. In this study, after incubating MCF-7 cells with DTX and DTX-H40-PLA NPs for $24 \mathrm{~h}$, considerable autophagosomes were induced (Fig. 6A and Fig. 6B), indicating that the chemotherapeutic drug-loaded NPs induced evident autophagy within the cancer cells. When the cells were co-treated with 3-MA, however, the induced autophagy was inhibited (Fig. 6A and Fig. 6B). On the other hand, when the cells were co-treated with $C Q$, the induced autophagosomes significantly accumulated (Fig. 6A and Fig. 6B). Additionally, LC3-II proteins also increased when the cells were treated with DTX and DTX-loaded H40-PLA NPs (Fig. 6C). Furthermore, CQ may accumulate autophagosomes by inducing lysosomal membrane permeabilization (Fig. 6D). In other words, inhibited by CQ and 3-MA, autophagy could be induced by DTX-loaded H40-PLANPs.

Since the DTX-H40-PLA NPs could induce autophagy and be sequestered by the autophagosomes into lysosome for degradation, co-delivery of chemotherapeutic drug and autophagy inhibitor is eligible for efficient drug delivery by nanoparticle formulation. Inhibition of autophagy can rescue the nanoparticles from endosome and lysosome, thus retaining the nanoparticles in the cytoplasm releasing the drugs $[6,12]$. Meanwhile, cancer cells can no longer resist chemotherapeutic drugs due to inhibited autophagy. Thus, chemotherapeutic drugs were combined with autophagy inhibitors in this study to promote cancer cell death. As shown in Fig. 7, the proliferation rates of MCF-7 cells treated with the DTX-H40-PLA NPs plummet in a time- and dose-dependent manner, and the survival rate of CQ-treated MCF-7 cells decreases apparently (Fig. 7). The $\mathrm{IC}_{50}$ values of MCF-7 cells incubated with the DTX-H40-PLA NPs and DTX-H40-PLA NPs+ CQ for 24, 48 and $72 \mathrm{~h}$ are listed in Table 2. The $\mathrm{IC}_{50}$ values of the drug formulated in the H40-PLA NPs after $24 \mathrm{~h}$ of treatment without autophagy inhibitor or with $30 \mu \mathrm{M}$ CQ were (32.29 \pm $1.41)$ and $(4.55 \pm 0.78) \mu \mathrm{g} / \mathrm{mL}$, respectively, suggesting that inhibition of autophagy by CQ could boost the in vitro therapeutic effects of the H40-PLA NPs by 7.0 fold. The similar results can be also obtained after $48 \mathrm{~h}$ and $72 \mathrm{~h}$ of treatment with CQ. (Table 2).

Table 2. IC 50 values of DTX formulation in the H40-PLA NPs alone or in combination with $30 \mu \mathrm{M} \mathrm{CQ}$ on MCF-7 cells following 24,48 and $72 \mathrm{~h}$ treatment, respectively $(n=6)$.

\begin{tabular}{lll}
\hline Incubation time $(\mathrm{h})$ & $\mathrm{IC}_{50}(\mu \mathrm{g} / \mathrm{mL})$ & \\
\hline & H40-PLANPs & H40-PLA NPs+CQ \\
\hline 24 & $32.29 \pm 1.41$ & $4.55 \pm 0.78$ \\
48 & $11.39 \pm 2.03$ & $0.18 \pm 0.07$ \\
72 & $2.61 \pm 0.73$ & $0.03 \pm 0.062$ \\
\hline
\end{tabular}

B

A

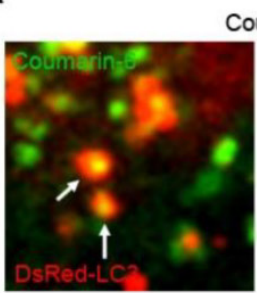

Coumarin-6-loaded H40-PLA NPs
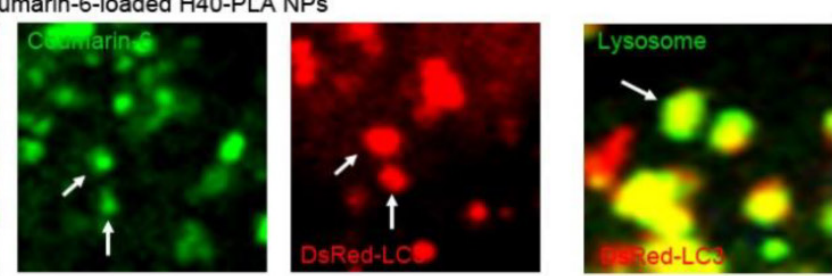

Drug-free H40-PLA NPs
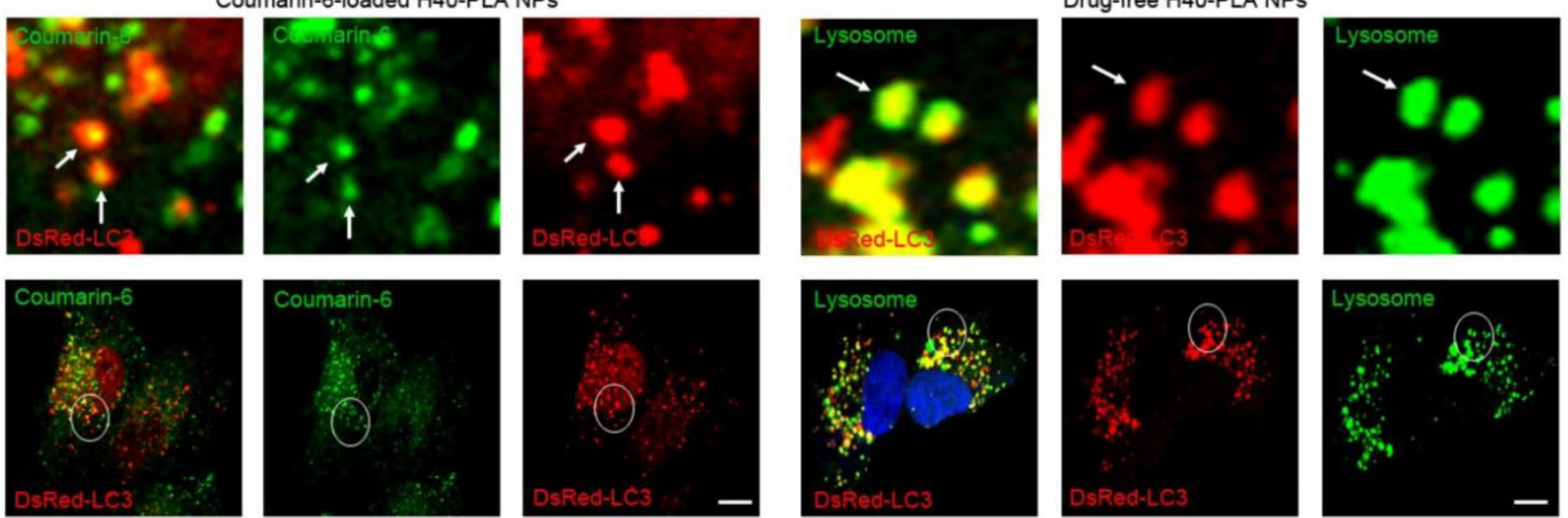
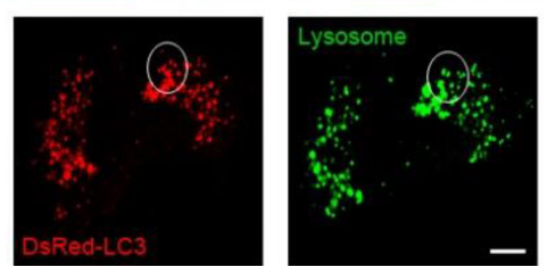

Figure 5. H40-PLA NPs were degraded through auto-lysosome pathway. (A) The H40-PLA NPs were sequestered by the autophagosomes (arrows). DsRed-LC3 transfected MCF-7 cells were treated with $100 \mu \mathrm{g} / \mathrm{mL}$ coumarin-6-loaded H40-PLA NPs for $24 \mathrm{~h}$. The above images are the enlarged ones in the white collar on the underside images. Scale bars: $10 \mu \mathrm{m}$. (B) The autophagosomes fuse with lysosomes (arrows). The above images are the enlarged ones in the white collar on the underside images. DsRed-LC3 transfected MCF-7 cells were treated with $100 \mu \mathrm{g} / \mathrm{mL}$ drug-free H40-PLA NPs for $24 \mathrm{~h}$, the lysosomes were detected with LAMPI antibody. Scale bars: $10 \mu \mathrm{m}$. 
A
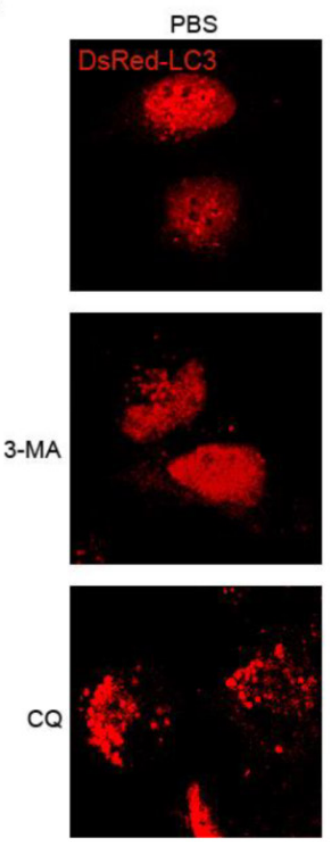

D

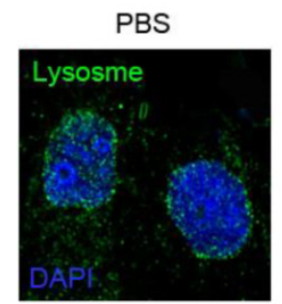

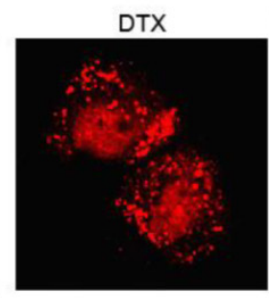
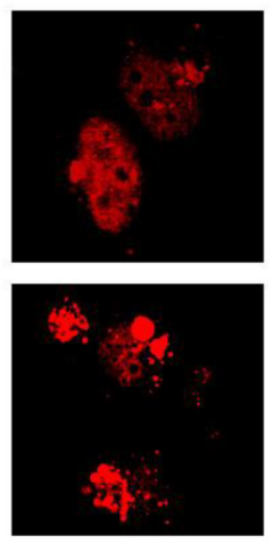

$C Q$

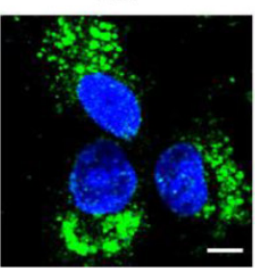

B
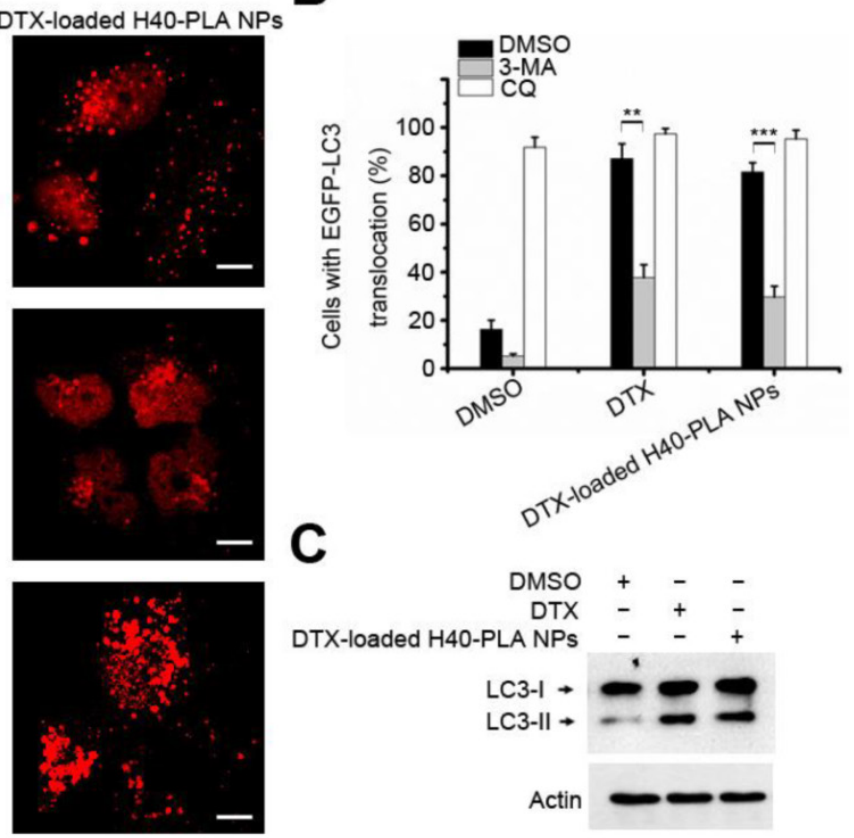

Figure 6. CQ inhibited autophagy induced by DTX-H40-PLA NPs. (A, B) Representative images and quantification of MCF-7 cells with DsRed-LC3 vesicles. The DsRed-LC3 transfected MCF-7 cells were co-treated with I $\mu$ M DTX and DTX-H40-PLA NPs for $24 \mathrm{~h}$, respectively. Scale bars: $10 \mu \mathrm{m}$. Data are shown as the mean \pm S.E.M. $* P<0.05$, $* *$ $P<0.01$, $* * * * 0.001$ compared to controls. (C) LC3I/II protein levels were analyzed by western blotting in the MCF-7 cells treated in (A). (D) MCF-7 cells were treated with 30 $\mu \mathrm{M} C \mathrm{CQ}$ for $24 \mathrm{~h}$, the lysosome detected with LAMPI antibody. Scale bars: $10 \mu \mathrm{m}$.

$24 \mathrm{~h}$

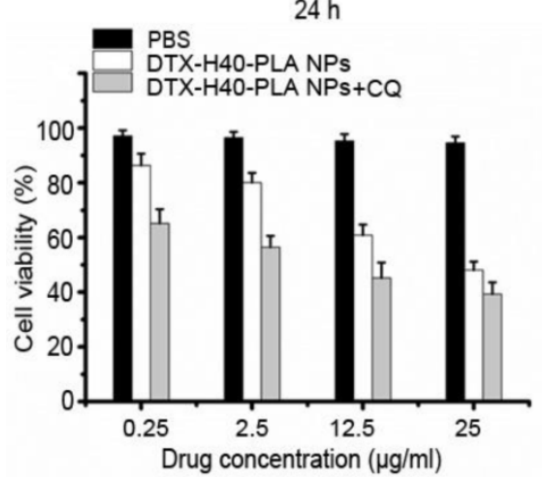

$48 \mathrm{~h}$

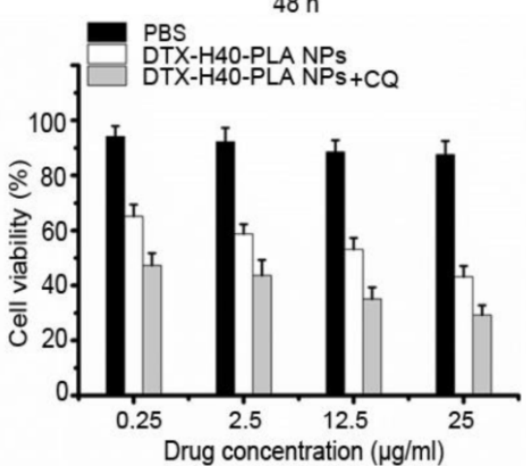

$72 \mathrm{~h}$

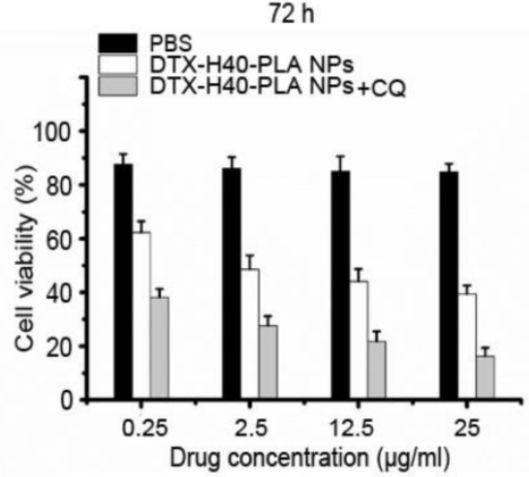

Figure 7. Viability of MCF-7 cells co-treated with DTX-H40-PLA NPs (equal to $0.25-25 \mu \mathrm{g} / \mathrm{ml}$ docetaxel) and $30 \mu \mathrm{M} \mathrm{CQ}$ for $24 \mathrm{~h}, 48 \mathrm{~h}$ and $72 \mathrm{~h}$, respectively.

\section{In vivo studies}

In order to investigate the in vivo curative effect of chemotherapeutic drug-loaded NPs in combination with autophagy inhibitors, a xenograft SCID mice model with MCF-7 cells implanted was used. Mice were intraperitoneal injected with DTX-H40-PLA NPs and $\mathrm{CQ}$ every 2 days for six consecutive cycles. Con- trol mice were injected with normal saline. The tumor size of the mice were measured and recorded every 2 days until the 12th day (Fig. 8A). Tumor growth was suppressed when the mice were treated with DTX-H40-PLA NPs and CQ, respectively (Fig. 8A-C). To confirm whether docetaxel could induce autophagy in vivo and whether CQ could block the fusion of autophagosomes with lysosome, immunofluores- 
cence histochemistry assay was carried out to detect the distribution of endogenous LC3 protein. As expected, DTX-H40-PLA NPs induced substantial autophagosomes within the tumor tissue (Fig. 8D). However, the autophagosomes accumulated significantly when the mice were treated with the DTX-H40-PLA NPs in combination with CQ (Fig. 8D).

When the mice were treated with chemotherapeutic drugs, autophagy was induced within the cancer cells that were then capable of resisting chemotherapeutic drug-induced apoptosis. Thus, co-treating the mice with autophagy inhibitor such as 3-MA or CQ managed to inhibit the formation of autophagosomes. In addition, the tumor cells stopped surviving owing to the inhibited autophagy that provided energy and nutrients. Therefore, it is practically promising to combine chemotherapeutic drugs-loaded NPs with autophagy inhibitors such as 3-MA and CQ for improve the effect of nanomedicine.
A

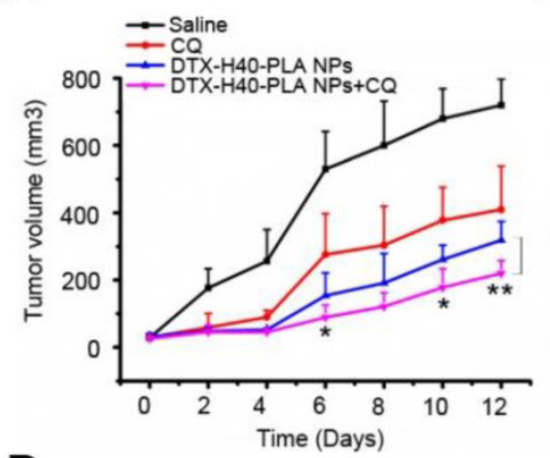

D
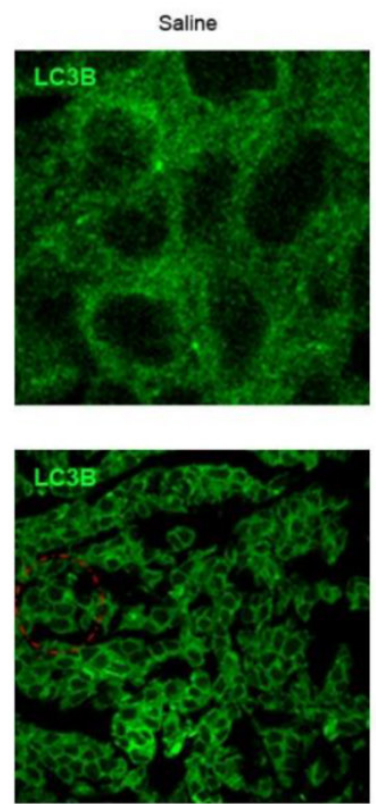

B

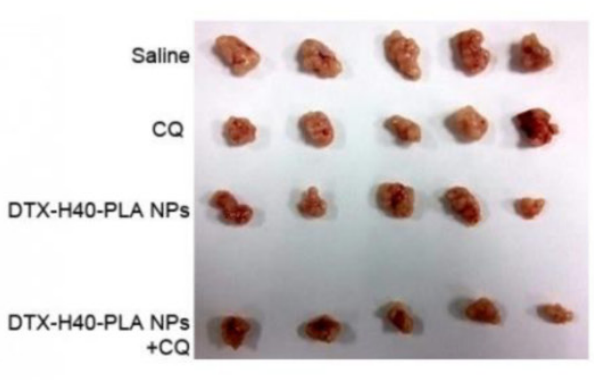

DTX-H40-PLA NPS
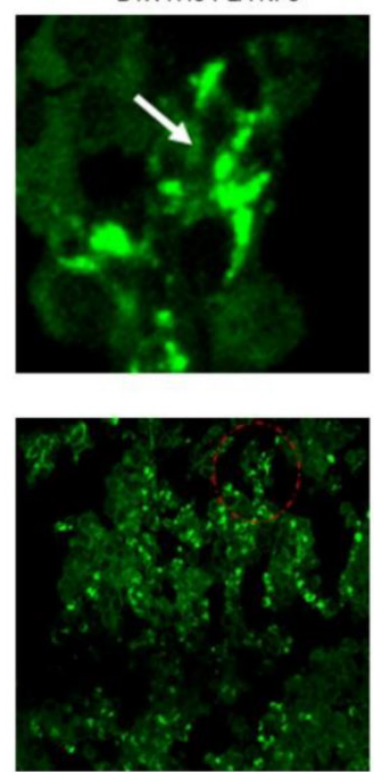

$C Q$
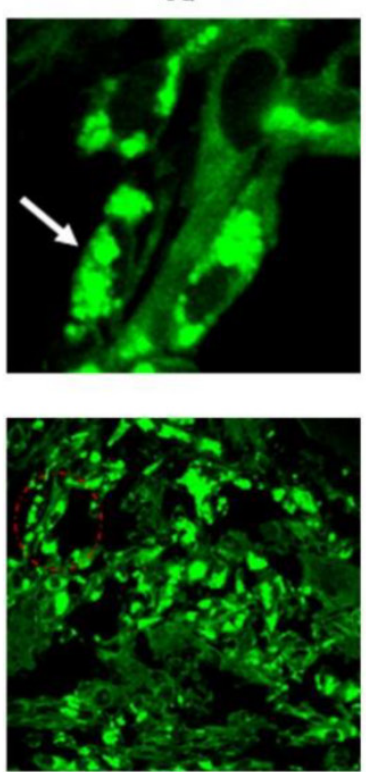

C

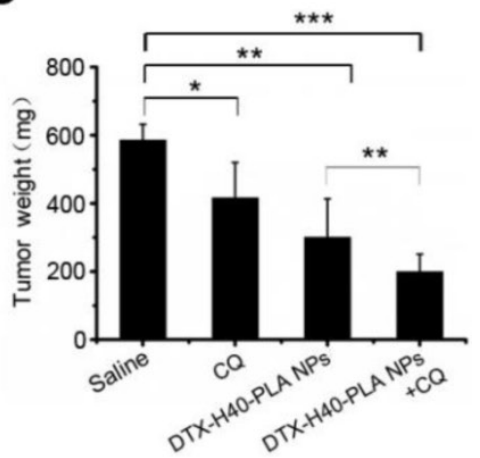

DTX-H40-PLA NPS +CQ
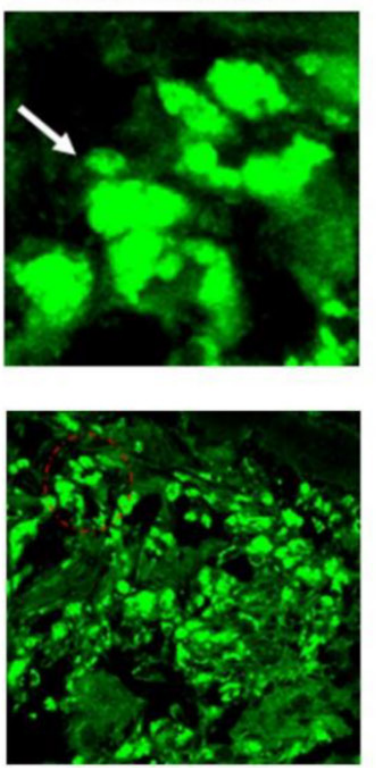

Figure 8. Inhibition of autophagy that induced by DTX-H40-PLA NPs by CQ enhances cancer cell killing in vivo. (A) Tumor growth curve of the SCID mice bearing MCF-7 cells xenograft after intratumoral injected with saline, DTX-H40-PLA NPs, CQ, and DTX-H40-PLA NPs in combination with CQ. Data are shown as the mean \pm S.E.M. *P<0.05, ** $P<0.01$ compared to DTX- H40-PLA NPs group. (B) Morphology of the tumors of each group taken out from the sacrificed mice at the study end point. (C) Tumor weight of each group at the study end point. Data are shown as the mean \pm S.E.M. $* P<0.05$, $* * P<0.01$, $* * * P<0.00$ I compared to controls or DTX-H40-PLA NPs group as indicated. (D) LC3 distribution in the tumor tissues of each group. Autophagosomes are indicated by the arrows. The above images are the enlarged ones in the red collar on the underside images. Scale bars: $10 \mu \mathrm{m}$.

\section{Conclusions}

DTX-loaded nanoparticles made of dendritic polymers (H40-PLA), i.e. DTX-H40-PLA NPs, were prepared and used as a model to evaluate whether the dendrimer-based NPs were sequestered by autophagy and degraded through the autophagic pathway.
Besides being degraded through the endolysosomal pathway, the nanoparticles of dendritic polymers were also sequestered by autophagosomes and fused with lysosomes (Fig. 9). In the meantime, DTX-H40-PLA NPs, which induced autophagy of the cancer cells, may lose the intrinsic advantages. DTX-H40-PLA NPs in combination with autophagy 
inhibitor CQ remarkably promoted death of cancer cells in vitro. In summary, combining chemotherapeutic drugs-loaded dendritic copolymer NPs with autophagy inhibitors is practically feasible for cancer treatment.

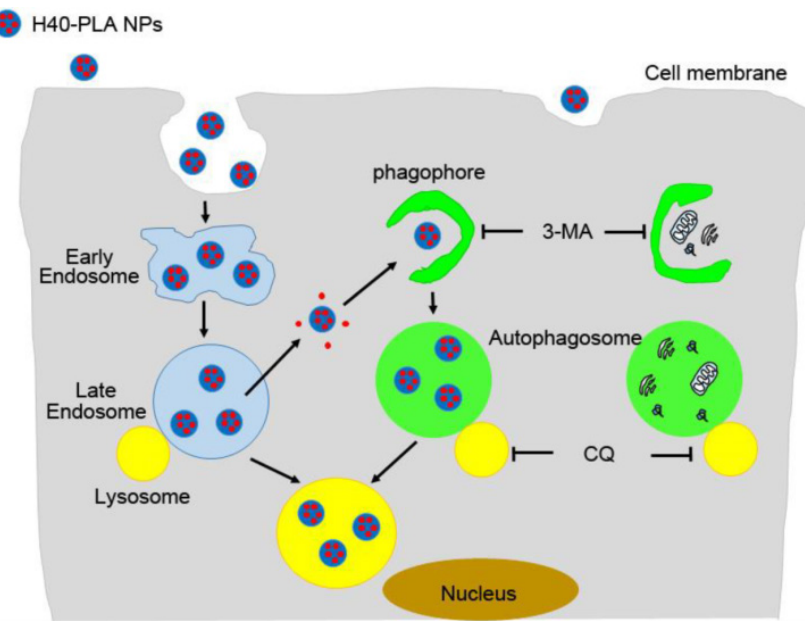

Figure 9. Schematic representation of the degradation pathway of H40-PLA NPs within cells.

\section{Acknowledgements}

This work was supported by the National Natural Science Foundation of China (No. 31270019, 51203085, 81302553), Program for New Century Excellent Talents in University (NCET-11-0275), Natural Science Foundation of Guangdong Province (No. S2012010010046, S2012040006820), and Science, Technology \& Innovation Commission of Shenzhen Municipality (No. JCYJ20120614191936420, JCYJ20120616213729920, JC201005270308A).

\section{Competing Interests}

The authors have declared that no competing interest exists.

\section{References}

1. Cheng Y, Zhao L, Li Y, Xu T. Design of biocompatible dendrimers for cancer diagnosis and therapy: current status and future perspectives. Chem Soc Rev. 2011:40:2673-703.

2. Lee CC, MacKay JA, Fréchet JM, Szoka FC. Designing dendrimers for biological applications. Nat Biotechnol. 2005;23(12):1517-26.

3. Mei L, Zhang Z, Zhao L, Huang L, Yang XL, Tang J, Feng SS. Pharmaceutical nanotechnology for oral delivery of anticancer drugs. Adv Drug Deliv Rev. 2013;65(6):880-90.

4. Muthu MS, Leong DT, Mei L, Feng SS. Nanotheranostics-application and further development of nanomedicine strategies for advanced theranostics. Theranostics. 2014;4(6):660-677.

5. Nanjwade BK, Bechra HM, Derkar GK, Manvi FV, Nanjwade VK. Dendrimers: emerging polymers for drug-delivery systems. Eur I Pharm Sci. 2009;38(3):185-96.

6. Mei L, Zhang X, Feng SS. Autophagy inhibition strategy for advanced nanomedicine. Nanomedicine. 2014;9(3):377-80

7. Yang Z, Klionsky DJ. Eaten alive: a history of macroautophagy. Nat Cell Biol 2010;12:814-22.

8. Levine B, Kroemer G. Autophagy in the pathogenesis of disease. Cell 2008;132:27-42.
9. Mizushima N, Komatsu M. Autophagy: renovation of cells and tissues. Cell 2011;147:728-41.

10. Li JJ, Hartono D, Ong CN, Bay BH, Yung LY. Autophagy and oxidative stress associated with gold nanoparticles. Biomaterials 2010;31: 5996-6003.

11. Halamoda Kenzaoui B, Chapuis Bernasconi C, Guney-Ayra S, Juillerat-Jeanneret L. Induction of oxidative stress, lysosome activation and autophagy by nanoparticles in human brain-derived endothelial cells. Biochem J 2012;441: 813-821.

12. Zhang X, Dong Y, Zeng X, Liang X, Li X, Tao W, Chen H, Jiang Y, Mei L, Feng SS. The effect of autophagy inhibitors on drug delivery using biodegradable polymer nanoparticles in cancer treatment. Biomaterials. 2014;35(6):1932-43.

13. Mathew R, Karantza-Wadsworth V, White E. Role of autophagy in cancer. Nat Rev Cancer 2007;7:961-7.

14. White E. Deconvoluting the context-dependent role for autophagy in cancer. Nat Rev Cancer 2012;12:401-10.

15. Karantza-Wadsworth V, White E. Role of autophagy in breast cancer. Autophagy 2007;3:610-3

16. Maycotte P, Aryal S, Cummings CT, Thorburn J, Morgan MJ, Thorburn A. Chloroquine sensitizes breast cancer cells to chemotherapy independent of autophagy. Autophagy 2012;8:200-12.

17. Maclean KH, Dorsey FC, Cleveland JL, Kastan MB. Targeting lysosomal degradation induces p53-dependent cell death and prevents cancer in mouse models of lymphomagenesis. J Clin Invest 2008;118:79-88.

18. Zeng X, Tao W, Mei L, Huang L, Tan C, Feng SS. Cholic acid-functionalized nanoparticles of star-shaped PLGA-vitamin E TPGS copolymer for docetaxel delivery to cervical cancer. Biomaterials 2013;34:6058-67.

19. Zhang Y, Tang L, Sun L, Bao J, Song C, Huang L, et al. A novel paclitaxel-loaded poly(epsilon-caprolactone)/Poloxamer 188 blend nanoparticle overcoming multidrug resistance for cancer treatment. Acta Biomater. 2010;6:2045-52.

20. Hoyer-Hansen M, Bastholm L, Szyniarowski P, Campanella M, Szabadkai G, Farkas T, et al. Control of macroautophagy by calcium, calmodulin-dependent kinase kinase-beta, and Bcl-2. Mol Cell 2007;25:193-205

21. Liang C, Feng P, Ku B, Dotan I, Canaani D, et al. Autophagic and tumour suppressor activity of a novel Beclin1-binding protein UVRAG. Nat Cell Biol 2006;8: 688-699.

22. Taylor CR, Levenson RM. Quantification of immunohistochemistry--issues concerning methods, utility and semiquantitative assessment II. Histopathology. 2006;49:411-24

23. Zhu Z, Li Y, Li X, Li R, Jia Z, Liu B, et al. Paclitaxel-loaded poly(N-vinylpyrrolidone)-b-poly(epsilon-caprolactone) nanoparticles: preparation and antitumor activity in vivo. J Control Release 2010;142:438-46.

24. Perrault SD, Walkey C, Jennings T, Fischer HC, Chan WC. Mediating tumor targeting efficiency of nanoparticles through design. Nano Lett 2009;9:1909-15.

25. Markovsky E, Baabur-Cohen $\mathrm{H}$, Eldar-Boock A, Omer L, Tiram G, Ferber S, Ofek P, Polyak D, Scomparin A, Satchi-Fainaro R. Administration, distribution, metabolism and elimination of polymer therapeutics. J Control Release. 2012;161(2):446-60

26. Tao W, Zeng X, Liu T, Wang Z, Xiong Q, Ouyang C, Huang L, Mei L. Docetaxel-loaded nanoparticles based on star-shaped mannitol-core PLGA-TPGS diblock copolymer for breast cancer therapy. Acta Biomater. 2013:9(11):8910-20.

27. Kabanov A, et al. Endocytosis of nanomedicines. J Control Release 2010;145: 182-195.

28. Yue ZG, Wei W, Lv PP, Yue H, Wang LY, Su ZG, et al. Surface charge affects cellular uptake and intracellular trafficking of chitosan-based nanoparticles. Biomacromolecules. 2011;12:2440-6.

29. Vasir JK, Labhasetwar V. Biodegradable nanoparticles for cytosolic delivery of therapeutics. Adv Drug Deliv Rev 2007;59:718-28.

30. Huotari J, Helenius A. Endosome maturation. EMBO J 2011;30:3481-500.

31. Mizushima N, Yoshimori T, Levine B. Methods in mammalian autophagy research. Cell. 2010;140:313-26.

32. Matsunaga K, Saitoh T, Tabata K, Omori H, Satoh T, Kurotori N, et al. Two Beclin 1-binding proteins, Atg14L and Rubicon, reciprocally regulate autophagy at different stages. Nat Cell Biol 2009;11:385-96. 